\title{
Large-scale flood risk assessment using a coupled model chain
}

\author{
Bruno Merz ${ }^{1, a}$, Heiko Apel ${ }^{1}$, Nguyen Viet Dung ${ }^{1}$, Daniela Falter ${ }^{1}$, Yeshewatesfa Hundecha ${ }^{2}$, Heidi Kreibich ${ }^{1}$, Kai Schröter $^{1}$, \\ Sergiy Vorogushyn ${ }^{1}$ \\ ${ }^{1}$ GFZ German Research Centre for Geosciences, Telegrafenberg, 14473 Potsdam, Germany \\ ${ }^{2}$ Swedish Meteorological and Hydrological Institute, 60176 Norrköping, Sweden
}

\begin{abstract}
Large-scale flood risk assessments are needed for a number of purposes, such as national strategic planning or re-insurance purposes. However, large-scale assessments are typically limited to hazard assessment and/or they are pieced together from smaller-scale assessments, leading to spatially inconsistent hazard and risk estimates. We present the coupled model chain RFM (Regional Flood Model) which is able to derive spatially consistent hazard and risk estimates for large scales (several $100,000 \mathrm{~km}^{2}$ ). It consists of a hydrological model, a coupled 1D-2D hydrodynamic model and a flood loss model. This model chain can be driven by observed meteorology, output from regional climate models or a weather generator. In this application, we demonstrate for river basins in Germany that this approach is able to provide spatially consistent large-scale patterns of hazard and risk. A multi-site, multi-variate weather generator provides 10,000 years of spatially consistent weather at daily resolution which is used as input for the model chain. This approach allows deriving discharge, inundation and damage patterns which respect spatial interactions within and beyond catchment boundaries.
\end{abstract}

\section{Introduction}

Flood risk results from the combination of flood hazard, exposure and vulnerability. Flood risk assessment requires quantifying all processes along the flood risk chain, from the flood-triggering precipitation through the hydrological processes in the catchment, the hydraulic processes in the river system, the behavior of flood defense measures to the damage mechanisms in the flood-affected areas.

Sophisticated flood risk assessment approaches have been developed for the local scale, for example for river reaches [1] or cities [2]. These local assessments often describe the different processes in considerable detail. Assessment methods for the scale of large river basins are less developed but have received increasing attention in recent years [3]. Large-scale assessments are often based on piecing together the results of local risk assessments, for instance, by estimating flood damage for different return periods that have been derived by at-site flood frequency analysis. However, the resulting flood maps and risk estimates do not give a correct large-scale representation [4]. Large-scale risk assessment methods should realistically represent the spatial heterogeneity of flood hazard and risk by incorporating the spatial dependence between the processes along the flood risk chain.

This contribution presents a simulation approach which aims at providing the complete space-time evolution of flood events at the scale of river basins. This approach has been termed 'Derived flood risk approach based on continuous simulation' and has been recently introduced by [5]. Here, risk is derived from very long simulations of the processes along the flood risk chain. A stochastic weather model generates very long time series of climate variables including their spatial dependence structure. This information is used as input to the subsequent model chain. This chain consists of a catchment model describing the runoff generation in the sub-catchments, a hydraulic model describing the processes in the river network and inundation areas, and a damage model for estimating flood damage. In this way, space-time fields for all processes along the risk chain, from the rainfall to the damage, are provided. Risk estimates are then derived from the simulated space-time fields of flood damage.

\section{Model chain}

To obtain space-time fields for the different processes, the multi-site, multivariate weather generator developed by [6] has been coupled to the Regional Flood Model (RFM) developed by [7]. In the following, the different elements of the model chain will be briefly introduced. Details can be found in [5-7].

The weather generator consists of two components. The first component generates daily precipitation at multiple sites by means of a multivariate-autoregressive model. A mixed distribution, consisting of the Gamma

\footnotetext{
${ }^{a}$ Corresponding author: bmerz@gfz-potsdam.de
} 
and the Generalized Pareto distribution, is used to represent daily precipitation amount. This approach is better able to capture extremes compared to the frequently used Gamma distribution which tends to underestimate rainfall extremes. The temporal and spatial dependence structures are accounted for through the spatial and auto-covariances of the observed precipitation computed after transforming the values at each station into a truncated standard normal variate. Truncation is performed to account for dry days on the basis of the proportion of dry days. A multivariate autoregressive model is then applied to generate correlated synthetic values drawn from a standard normal variate at all stations, which are finally back transformed to the appropriate distribution fitted to the data at each station. The second component generates minimum, mean and maximum temperature, solar radiation and relative humidity at multiple locations, using a similar approach as the precipitation component. The distributions are fitted conditional to whether the day is wet or dry. Both components are parameterized on a monthly basis. Details of the weather generator are given in [6].

The output of the weather generator is used as input to the catchment model SWIM (Soil and Water Integrated Model, [8]). SWIM is a conceptual, semi-distributed model for hydrological and water quality modelling. The river basin is subdivided into sub-basins and further into hydrotopes (or hydrological response units). Within a given sub-basin, hydrotopes are delineated based on land use, soil types and groundwater table. The hydrotopes within a sub-basin are assumed to behave in a hydrologically uniform way. The hydrological processes and their vertical and lateral fluxes are calculated for each hydrotope and then aggregated to the sub-basin scale. The total sub-basin runoff is routed according to the river network topology by the Muskingum approach. SWIM simulates the hydrological processes at daily resolution.

To transfer the flow information from SWIM into inundation areas, a coupled 1D/2D hydraulic model has been developed which simulates dike overtopping and hinterland inundation. The $1 \mathrm{D}$ river network module simulates the water flow along the river between the dikes. The hydraulic model is only initiated in situations when bankfull flow is reached. Flow exceeding bankfull discharge is simulated by means of the diffusive wave equations describing water flow in open channels. When the flow depth exceeds the dike crest height, overtopping occurs and the 2D hinterland inundation model is triggered. Outflow into the hinterland is calculated with the broad-crested weir equation. The inundation propagation is simulated with the $2 \mathrm{D}$ raster-based inertia model proposed by [9]. The floodplain is discretized into a computational grid of regular cells. The 1D and 2D models are coupled in every time step to restrict the flow into the dike hinterland in case the water level in the hinterland reaches the water level in the channel. The $1 \mathrm{D} / 2 \mathrm{D}$ coupled models are implemented in the CUDA Fortran environment (PGI, Lake Oswego, Oregon, USA) to enable simulation on highly parallelized NVIDIA Graphical Processor Units (GPU; NVIDIA, Santa Clara, California, USA) and multicore processor Central
Processing Unit (CPU). Details on the hydraulic model can be found in [7].

The resulting time series of inundation areas are used as input to the subsequent damage estimation. The current version of RFM estimates the building damage to private households, although the consideration of other damage types is possible. Damage is estimated as the product of relative building loss and assets. Relative building loss is derived by applying the rule based, multivariable Flood LOss MOdel for the private sector FLEMOps+r [10]. It considers inundation depth, return period, building quality, building type, precautionary measures and contamination as input variables to estimate relative loss to residential buildings. The base model version FLEMOps has been derived on the microscale, i.e. for individual buildings, using 1,697 empirical damage cases that have been collected via computer aided telephone interviews after the flood in 2002 in the Elbe and Danube catchments in Germany [11]. For largescale applications with RFM, the damage model is applied on the meso-scale, i.e. on the level of aggregated land use classes. All input variables are prepared as gridded data sets with a spatial resolution that complies with the output of the 2D grid-based inundation model. Maximum inundation depth is available as output of the $2 \mathrm{D}$ inundation model. Inundation return periods are estimated within each sub-basin of the hydrologic model component. The remaining input variables for the damage model and the assets values have to be provided externally. Absolute flood losses per grid cell are finally calculated as the product of location-dependent relative building damage and location-dependent asset values. Details on the damage model and its parameterization can be found in $[5,7]$.

\section{MODEL APPLICATION}

\subsection{Model setup}

The complete model chain was applied to the Elbe river basin and one of its sub-basins, the Mulde catchment. The Elbe river basin covers an area of $148,000 \mathrm{~km}^{2}$. One of the major tributaries in the German part of the Elbe is the Mulde River with a catchment size of 7,400 $\mathrm{km}^{2}$. The Elbe and the Mulde have been severely affected by recent floods, for example in August 2002 and June 2013.

The weather generator and the SWIM model were set up for all river basins in Germany, including their upstream areas outside of Germany (Figure 1). This region covers the 5 major river basins Rhine, Danube, Elbe, Weser and Ems and has a size of $444,000 \mathrm{~km}^{2}$. The $1 \mathrm{D} / 2 \mathrm{D}$ hydraulic model and the damage model were implemented for the Elbe basin, including the Mulde catchment. The first application to the Elbe basin showed that, although the overall results were plausible, errors and uncertainties of the model chain were significant. The largest source of errors was the low quality of the floodplain and dike cross sections. In a second application to the Mulde catchment, a higher resolution topographic data $(10 \mathrm{~m}$ instead of $25 \mathrm{~m}$ resolution of the 
Digital Elevation Model) and an additional preprocessing step (by manually checking the plausibility of the cross sections) resulted in significantly better simulation of inundation areas.

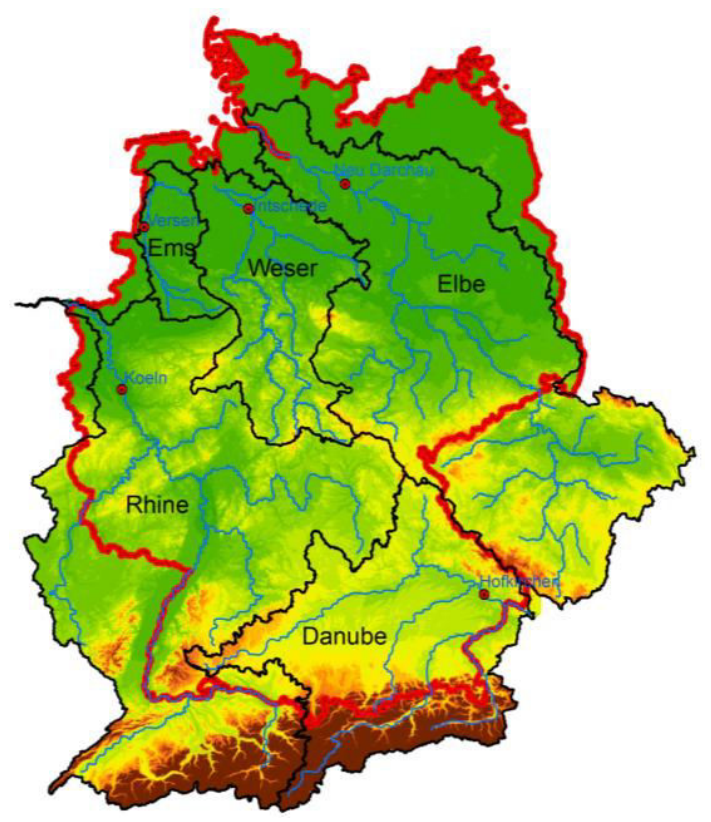

Figure 1. The 5 major river basins in Germany, including their upstream areas outside of Germany.

The weather generator was parameterized taking into account daily climate observations for the period 19512003 for 528 stations. It was used to generate 100 time series of 100 years, i.e. 10,000 years, with daily weather for all 528 climate stations. These data sets were fed into SWIM to calculate daily time series of catchment hydrology for all 5 major river basins. The SWIM implementation for the different basins contains different numbers of sub-basins, e.g. the Elbe basin was divided into 2,268 sub-basins. The hydraulic model was implemented for the German part of the Elbe River Basin covering an area of $66,000 \mathrm{~km}^{2}$ and a river network of $2,730 \mathrm{~km}$. This resolution considers river segments that have a drainage area of at least $600 \mathrm{~km}^{2}$. The $2 \mathrm{D}$ rasterbased inundation model was set up on a computational grid of $100 \mathrm{~m}$ which was resampled from the $10 \mathrm{~m}$ DEM. The 2D domain for the German part of the Elbe River Basin consists of a grid of 11,400,000 cells while that for the Mulde catchment consists of 1,368,171 cells.

The damage model was applied at the $100 \mathrm{~m}$ grid of the 2D inundation model. The input variables building type and building quality and the asset values of the regional stock of residential buildings were estimated based on a number of data sets, such as the INFAS Geodaten data set (Infas Geodaten Infas Geodaten $\mathrm{GmbH}$, 2009) and German ATKIS data (Authoritative Topographic Cartographic Information System, 2009). Detailed information about the data sets and about the calibration of the model chain can be found in $[5,7]$.

\subsection{Simulating flood risk at the scale of large river basins}

Figure 2 shows a comparison of the spatial dependence between observed and generated precipitation for the 528 climate stations and covering the region shown in Figure 1. For each pair of climate stations in the data set, the correlation coefficient $\mathrm{R}$ is calculated and plotted as function of the distance between the stations. Figure 2 demonstrates that the multi-site weather generator plausibly represents the spatial dependence, i.e. the decrease of correlation with increasing station distance. However, the spread of the correlation coefficient in the observational data set is somewhat larger than in the synthetic data set.

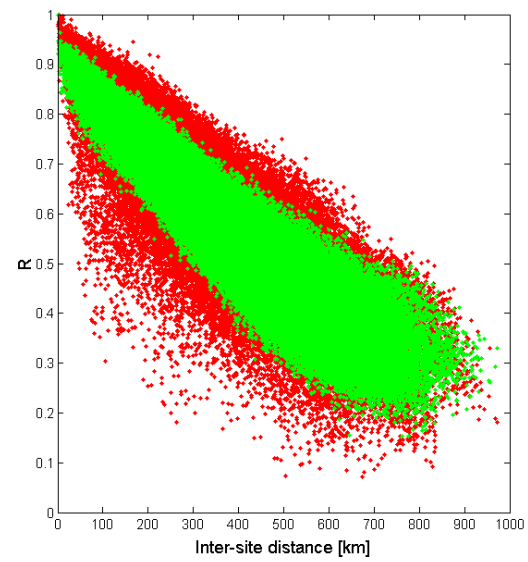

Figure 2. Comparing the spatial dependence of observed (red) and synthetically generated (green) precipitation.
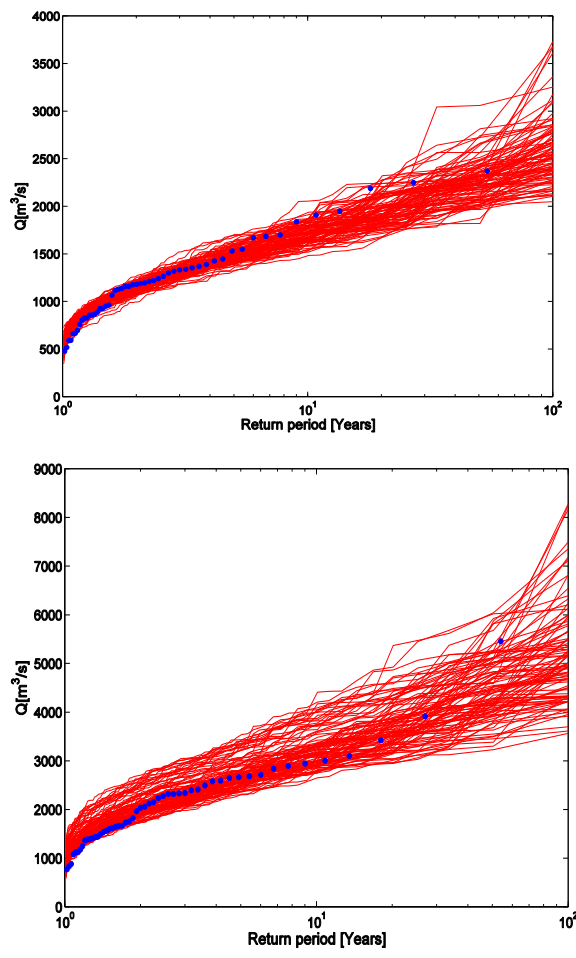

Figure 3. Comparison of flood frequency curves derived from observations (blue) and from generated streamflow (red) for gauge Inschede/Weser (top), and for gauge Neu Darchau/Elbe (bottom). 
Figure 3 shows flood frequency curves for two streamflow stations in the Elbe and Weser river basins (for locations see Figure 1). Flood frequencies derived from observations are compared to frequency curves based on synthetic data from the output of the model chain 'weather generator - SWIM model'. For each 100year period, one frequency curve is derived leading to 100 curves. These 100 curves embed the observational flood frequency curve and demonstrate that the approach leads to plausible estimates of flood frequencies.

Propagating the output of the hydrological model through the $1 \mathrm{D} / 2 \mathrm{D}$ hydraulic model and further through the damage model results in a set of flood events whereas the space-time dynamics of the inundation areas and of the damages respect the spatial dependence of all the processes along the flood risk chain that lead to inundation and damage. For the simulation period of 100 x 100 years and the Mulde catchment, 2,000 flood inundation events occurred. This data set of 2,000 events can be used to derive risk statements at any desired location within the model area and at any spatial scale.

Figure 4 shows exemplarily one of the results for the Mulde catchment. The spatial distribution of three flood events is given, whereas each flood event resulted in the same damage (approximately 68 million Euro). However, the spatial distribution of flood damage within the catchment is very diverse between the events. For example, the return period in the eastern tributary (subcatchment 1004) varies between 0 and 18.5 million Euro which is equal to a variation in return period between 1 and 1,206 years.

This example illustrates one of the advantages of the approach. Due to the possibility of simulating very long time series of the complete flood risk chain, the chances are high that rare events are simulated that are generated by an unfavorable combination of the different processes. For example, a given configuration of catchment, river and assets may lead to extreme damages for a certain superposition of catchment state and event precipitation. Due to the complexity of the 'atmosphere - catchment river - assets' system, it is, however, not clear which combinations of space-time fields of precipitation and catchment state lead to extreme events. Using the output from a weather generator in combination with a model chain such as RFM explores the high-dimensional space of variables in order to detect such critical cases that lead to extremes.

\section{Conclusions}

This contribution demonstrates that it is feasible to simulate the complete flood risk chain for large river basins in a continuous simulation mode with high temporal and spatial resolution. The temporal resolution of 1 day and spatial resolution of $100 \mathrm{~m}$ for inundation and damage simulation has the potential to provide adequate space-time patterns of the involved processes.

RFM plausibly represents the various processes along the flood risk chain. Differences between simulation and observations can be mainly attributed to processes that are not included in the current setup, namely water management measures in catchments, dike breaching, and flooding of smaller tributaries.

Further, we conclude that the 'Derived flood risk approach based on continuous simulation' introduced by [5] is able to generate plausible realizations of flood events that (1) respect the spatial dependence of the processes along the flood risk chain, and (2) represent a wide variety of flood events mimicking the heterogeneity of real flood events. However, more work is needed to understand the reliability of the model chain and the derived risk statements.

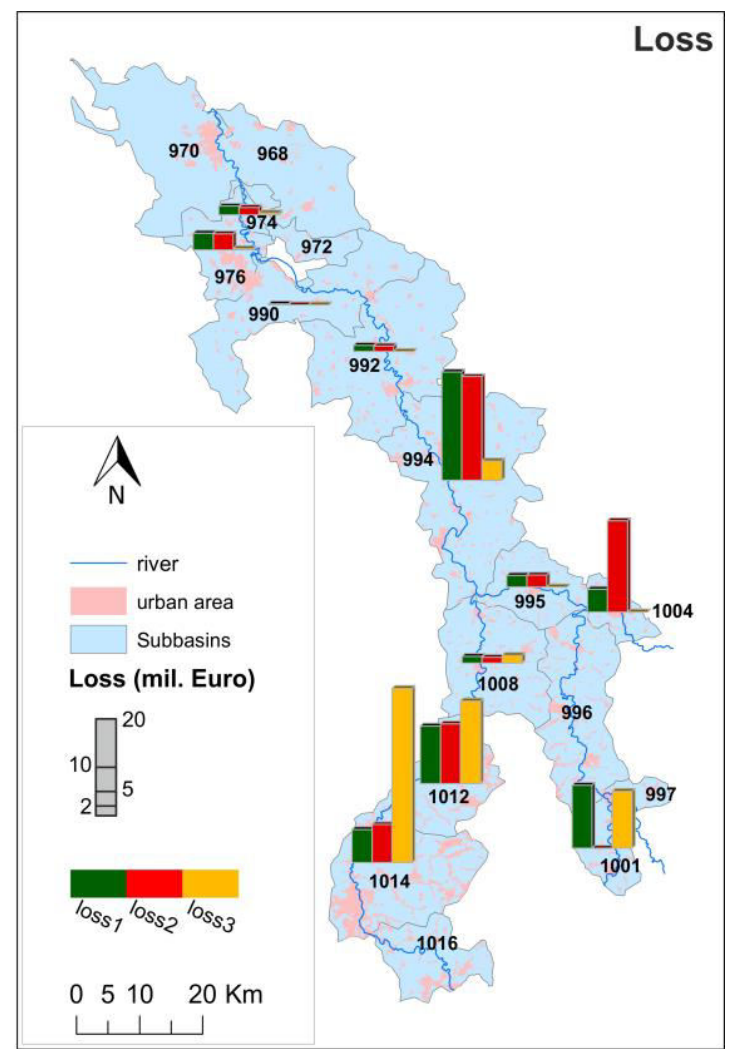

Figure 4. Spatial distribution of damages at the sub-basin level for three synthetically generated flood events. Each event leads to the same overall damage for the Mulde catchment, however, the spatial distribution of losses within the catchment is very different between the events.

\section{References}

1. Vorogushyn, S., Lindenschmidt, K.-E., Kreibich, H., Apel, H., Merz, B. (2012). Analysis of the detention basin impact on dike failure probabilities and flood risk for a complex channel-dike-floodplain system, Journal of Hydrology, 436-437, 120-131

2. Merz, B, Thieken, A.H. (2009). Flood risk curves and uncertainty bounds, Naural Hazards, 51, 437458

3. Moel, H. de, Jongman, B., Kreibich, H., Merz, B., Penning-Rowsell, E., Ward, P. (2015). Flood risk assessments at different spatial scales, Mitigation and Adaptation Strategies for Global Change, 20(6), 865-890 
4. Thieken, A.H., Apel, H., Merz, B. (2015). Assessing the probability of large-scale flood loss events - a case study for the river Rhine, Germany, Journal of Flood Risk Management, 8(3), 247-262

5. Falter, D., Schröter, K., Nguyen, D., Vorogushyn, S., Kreibich, H., Hundecha, Y., Apel, H., Merz, B. (2015). Spatially coherent flood risk assessment based on long-term continuous simulation with a coupled model chain, Journal of Hydrology, 524, 182-193

6. Hundecha, Y., Pahlow, M., Schumann, A. (2009). Modeling of daily precipitation at multiple locations using a mixture of distributions to characterize the extremes, Water Resources Research, 45(12), W12412

7. Falter, D., Nguyen, D., Vorogushyn, S., Schröter, K., Hundecha, Y., Kreibich, H., Apel, H., Theisselmann, F., Merz, B. (2016). Continuous, large-scale simulation model for flood risk assessments: proofof-concept, Journal of Flood Risk Management, 9(1), 3-21

8. Krysanova, V., Müller-Wohlfeil, D., Becker, A. (1998). Development and test of a spatially distributed hydrological/water quality model for mesoscale watersheds, Ecol. Model., 106, 261-289

9. Bates, P. D., Horritt, M.S., Fewtrell, T.J. (2010). A simple inertial formulation of the shallow water equations for efficient two-dimensional flood inundation modelling, Journal of Hydrology, 387, 33-45

10. Elmer, F., Thieken, A. H., Pech, I., Kreibich, H. (2010). Influence of flood frequency on residential building losses, Natural Hazards and Earth System Sciences, 10, 2145-2159

11. Thieken, A., Müller, M., Kreibich, H., Merz, B. (2005). Flood damage and influencing factors: New insights from the August 2002 flood in Germany, Water Resources Research, 41, W12430. 